\title{
Homotopy Perturbation Method for Fractional Black-Scholes European Option Pricing Equations Using Sumudu Transform
}

\author{
Asma Ali Elbeleze, ${ }^{1}$ Adem Kılıçman, ${ }^{2}$ and Bachok M. Taib ${ }^{1}$ \\ ${ }^{1}$ Faculty of Science and Technology, Universiti Sains Islam Malaysia, 71800 Nilai, Malaysia \\ ${ }^{2}$ Department of Mathematics, Faculty of Science, University Putra Malaysia, 4300 Serdang, Selangor, Malaysia \\ Correspondence should be addressed to Adem Kılıçman; akilicman@putra.upm.edu.my
}

Received 12 March 2013; Revised 7 April 2013; Accepted 13 April 2013

Academic Editor: Guo-Cheng Wu

Copyright ( 2013 Asma Ali Elbeleze et al. This is an open access article distributed under the Creative Commons Attribution License, which permits unrestricted use, distribution, and reproduction in any medium, provided the original work is properly cited.

The homotopy perturbation method, Sumudu transform, and He's polynomials are combined to obtain the solution of fractional Black-Scholes equation. The fractional derivative is considered in Caputo sense. Further, the same equation is solved by homotopy Laplace transform perturbation method. The results obtained by the two methods are in agreement. The approximate analytical solution of Black-Scholes is calculated in the form of a convergence power series with easily computable components. Some illustrative examples are presented to explain the efficiency and simplicity of the proposed method.

\section{Introduction}

Fractional differential equations have attracted much attention, recently, see, for instance [1-5]. This is mostly due to the fact that fractional calculus provides an efficient and excellent instrument for the description of many practical dynamical phenomena arising in engineering and scientific disciplines such as, physics, chemistry, biology, economy, viscoelasticity, electrochemistry, electromagnetic, control, porous media, and many more, see, for example, [6-9].

Many partial differential equations of fractional order have been studied and solved. For example many researchers studied the existence of solutions of the Black-Scholes model using many methods, see [10-14].

The homotopy perturbation method was first introduced and applied by He [15-17]. This method has been applied by many authors in many fields, for example, it is applied to nonlinear oscillator [18], nonlinear wave equation [19], nonlinear partial differential equations [20], integro-differential equation of fractional order [21], fuzzy differential equation [22], and other fields [23, 24]. Further homotopy perturbation methods are combined with Laplace transform to solve many problems such as one dimensional nonhomogeneous partial differential equations with a variable coefficient [25],
Black-Scholes of fractional order [26], and parabolic partial differential equations [27]. The homotopy perturbation method coupled with Sumudu transform basically illustrates how Sumudu transform can be used to approximate the solutions of the linear and nonlinear differential equations by manipulating the homotopy perturbation method. In [28] Singh et al. studied the solution of linear and nonlinear partial differential equations by using the homotopy perturbation method coupled with Sumudu transform. Further, in [29] the authors proposed the homotopy perturbation method coupled with Sumudu transform to solve nonlinear fractional gas dynamics equation.

The Black-Scholes equation is one of the most significant mathematical models for a financial market. It is a secondorder parabolic partial differential equation that governs the value of financial derivatives. This Black-Scholes model for the value of an option is described by the following equation:

$$
\begin{array}{r}
\frac{\partial v}{\partial t}+\frac{\sigma x^{2}}{2} \frac{\partial^{2} v}{\partial x^{2}}+r(t) x \frac{\partial v}{\partial x}-r(t) v=0, \\
(x, t) \in R^{+} \times(0, T), \quad 0<\alpha \leq 1,
\end{array}
$$

where $v(x, t)$ is the European call option price at asset price $x$ and at time $t, T$ is the maturity, $r(t)$ is the risk free 
interest rate, and $\sigma(x, t)$ represents the volatility function of underlying asset. The payoff functions are

$$
v_{c}(x, t)=\max (x-E, 0) ; \quad v_{p}(x, t)=\max (E-x, 0),
$$

where $v_{c}(x, t)$ and $v_{p}(x, t)$ are the value of the European call and put options, respectively, $E$ denotes the expiration price for the option, and the function $\max (x, 0)$ gives the large value between $x$ and 0 .

In this paper, we consider the following fractional BlackScholes of the form

$$
\begin{array}{r}
\frac{\partial^{\alpha} v}{\partial t^{\alpha}}+\frac{\sigma x^{2}}{2} \frac{\partial^{2} v}{\partial x^{2}}+r(t) x \frac{\partial v}{\partial x}-r(t) v=0 \\
(x, t) \in R^{+} \times(0, T), \quad 0<\alpha \leq 1 .
\end{array}
$$

In [29] Singh et al. used homotopy perturbation method coupled with Sumudu transform to solve fractional gas dynamics equation. The aim of this paper is to applied the homotopy perturbation method for fractional Black-Scholes equation by using He's polynomials and Sumudu transform.

\section{Sumudu Transform}

The Sumudu transform was first introduced and applied by Watugala [30] in (1998). For further details and properties of Sumudu transform see [31-34]. The Sumudu transform is defined over the set of functions:

$$
\begin{aligned}
A=\{ & f(t): \exists M, \tau_{1}, \tau_{2}>0,|f(t)|<M e^{t / \tau_{j}}, \\
& \text { if } \left.t \in(-1)^{j} \times[0, \infty)\right\}
\end{aligned}
$$

by the following formula

$$
\bar{f}(u)=S[f(t) ; u]=: \int_{0}^{\infty} f(u t) e^{-} t d t, \quad u \in(-\tau, \tau) .
$$

The existence and uniqueness was discussed in [35]. For further properties of Sumudu transform and its derivatives, see [36]. Some fundamental further established properties of Sumudu transform can be found in [31].

Similarly, this new transform was applied to one-dimensional neutron transport equation [37]. In [34] Kilıçman et al. show that there is a strong relationship between Sumudu and other integral transforms. Further in [33] the Sumudu transform was extended to the distributions, and some of their properties were also studied in [38]. Recently Kilıçman et al. applied this transform to solve system of differentials equations, for more details see [34, 35, 37-39].

\section{Basic Definitions of Fractional Calculus}

In this section, we give some basic definitions and properties of fractional calculus theory which will be used in this paper.
Definition 1. The Riemann-Liouville fractional integral operator of order $\alpha \geq 0$ of a function $f \in C \mu, \mu \geq-1$ is defined as follows:

$$
\begin{array}{r}
J^{\alpha} f(x)=\frac{1}{\Gamma(\alpha)} \int_{0}^{x}(x-t)^{\alpha-1} f(t) d t \\
\alpha>0, t>0
\end{array}
$$

in particular $J^{0} f(x)=f(x)$.

For Riemann-Liouville fractional integral, one has

$$
J^{\alpha} x^{\gamma}=\frac{\Gamma(\gamma+1)}{\Gamma(\alpha+\gamma+1)} x^{\alpha+\gamma} .
$$

Definition 2. The Caputo fractional derivative of $f \in C_{-1}^{m}$, $m \in N$ is defined as follows:

$$
\begin{array}{r}
D^{\alpha} f(x)=\frac{1}{\Gamma(m-\alpha)} \int_{0}^{x}(x-t)^{m-\alpha-1} f^{m}(t) d t \\
m-1<\alpha \leq m .
\end{array}
$$

Lemma 3. If $m-1<\alpha \leq m, m \in N, f \in C_{\mu}^{m}, \mu>-1$ then the following two properties hold:

(1) $D^{\alpha}\left[J^{\alpha} f(x)\right]=f(x)$,

(2) $J^{\alpha}\left[D^{\alpha} f(x)\right]=f(x)-\sum_{k=1}^{m-1} f^{k}(0)\left(x^{k} / k !\right)$.

Definition 4. The Mittag-Leffler function $E_{\alpha}(z)$ with $\alpha>0$ is defined by the following series representation, valid in the whole complex plane:

$$
E_{\alpha}(z)=\sum_{0}^{\infty} \frac{z^{n}}{\Gamma(\alpha n+1)}
$$

Definition 5. The Sumudu transform of the Caputo fractional derivative is defined as follows [40]:

$$
\begin{array}{r}
S\left[D_{t}^{\alpha} f(t)\right]=u^{-\alpha} S[f(t)]-\sum_{k=0}^{m-1} u^{-\alpha+k} f^{(k)}\left(0^{+}\right), \\
(m-1<\alpha \leq m) .
\end{array}
$$

\section{Homotopy Perturbation Method}

To illustrate the basic idea of this method, we consider the following nonlinear differential equation:

$$
A(u)-f(r)=0, \quad r \in \Omega
$$

with boundary conditions

$$
B\left(u, \frac{\partial u}{\partial n}\right)=0, \quad r \in \Gamma
$$

where $A$ is a general differential operator, $B$ is a boundary operator, $f(r)$ is a known analytic function, and $\Gamma$ is the boundary of the domain $\Omega$. 
In general, the operator $A$ can be divided into two parts $L$ and $N$, where $L$ is linear, while $N$ is nonlinear. Equation (11) therefor can be rewritten as follows:

$$
L(u)+N(u)-f(r)=0
$$

By the homotopy technique $[41,42]$ we construct a homotopy $v(r, p): \Omega \times[0,1] \rightarrow R$ which satisfies

$$
\begin{array}{r}
H(v, p)=(1-p)\left[L(v)-L\left(u_{0}\right)\right]+p[A(v)-f(r)]=0 \\
p \in[0,1], r \in \Omega
\end{array}
$$

or

$$
H(v, p)=L(v)-L\left(u_{0}\right)+p L\left(u_{0}\right)+p[N(v)-f(r)]=0,
$$

where $p \in[0,1]$ is an embedding parameter, and $u_{0}$ is an initial approximation of (11) which satisfies the boundary conditions.

From (14) and (15) we have

$$
\begin{aligned}
& H(v, 0)=L(v)-L\left(u_{0}\right)=0 \\
& H(v, 1)=A(v)-f(r)=0 .
\end{aligned}
$$

The changing in the process of $p$ from zero to unity is just that of $v(r, p)$ from $u_{0}(r)$ to $u(r)$. In topology this is called deformation, and $L(v)-L\left(u_{0}\right)$ and $A(v)-f(r)$ are called homotopic.

Now, assume that the solution of (14), (15) can be expressed as

$$
v=v_{0}+p v_{1}+p^{2} v_{2}+\cdots
$$

Setting $p=1$ results in the approximate solution of (11):

$$
u=\lim _{p \rightarrow 1} v=v_{0}+v_{1}+v_{2}+\cdots
$$

\section{Homotopy Perturbation Method Coupled with Sumudu Transform}

To illustrate the basic idea of this method, we consider the following nonlinear fractional differential equation:

$$
\begin{array}{r}
D_{t}^{\alpha} u(x, t)+L[x] u(x, t)+N[x] u(x, t) \\
=q(x, t), \quad t>0, m-1<\alpha \leq m,
\end{array}
$$

where $D_{t}^{\alpha}=\partial^{\alpha} / \partial t^{\alpha}$ is the fractional Caputo derivative of the function $u(x, t), L$ is the linear differential operator, $N$ is the nonlinear differential operator, and $q(x, t)$ is the source term.

Now, applying the Sumudu transform on both sides of (19), we have

$$
\begin{gathered}
S\left[D_{t}^{\alpha} u(x, t)\right]+S[L[x] u(x, t)+N[x] u(x, t)] \\
\quad=S[q(x, t)] .
\end{gathered}
$$

Using the differential property of Sumudu transform, we have

$$
\begin{aligned}
S[u(x, t)] & \\
= & f(x)-u^{\alpha} S[L[x] u(x, t)+N[x] u(x, t)] \\
& +u^{\alpha} S[q(x, t)] .
\end{aligned}
$$

Operating with Sumudu inverse on both sides of (21)

$$
u(x, t)=Q(x, t)-S^{-1}\left[u^{\alpha} S(L[x] u(x, t)+N[x] u(x, t))\right],
$$

where $Q(x, t)$ represents the term arising from the source term and the prescribed initial conditions.

Now, applying the classical homotopy perturbation technique, the solution can be expressed as a power series in $p$ as given below:

$$
u(x, t)=\sum_{n=0}^{\infty} p^{n} u_{n}(x, t)
$$

where the homotopy parameter $p$ is considered as a small parameter $(p \in[0,1])$.

We can decompose the nonlinear term as

$$
N u(x, t)=\sum_{n=0}^{\infty} p^{n} H_{n}(u),
$$

where $H_{n}$ are He's polynomials of $u_{0}, u_{1}, u_{2}, \ldots, u_{n}$ [43-45], and it can be calculated by the following formula:

$$
\begin{aligned}
H & \left(u_{0}, u_{1}, u_{2}, \ldots, u_{n}\right) \\
& =\frac{1}{n !} \frac{\partial^{n}}{\partial p^{n}}\left[N\left(\sum_{n=0}^{\infty} p^{i} u_{i}\right)\right]_{p=0}, \quad n=0,1,2, \ldots
\end{aligned}
$$

By substituting (23) and (24) and using HPM [15] we get

$$
\begin{aligned}
\sum_{n=1}^{\infty} p^{n} u_{n}(x, t) & \\
= & Q(x, t) \\
& -p\left(S^{-1}\left[u^{\alpha} S\left[L \sum_{n=0}^{\infty} p^{n} u_{n}(x, t)+\sum_{n=0}^{\infty} p^{n} H_{n}(u)\right]\right]\right) .
\end{aligned}
$$

This is coupling of Sumudu transform and homotopy perturbation method using He's polynomials. By equating the coefficient of corresponding power of $p$ on both sides, the following approximations are obtained as

$$
\begin{aligned}
& p^{0}: u_{0}(x, t)=Q(x, t), \\
& p^{1}: u_{1}(x, t)=-S^{-1}\left(u^{\alpha} S\left[L[x] u_{0}(x, t)+H_{0}(u)\right]\right), \\
& p^{2}: u_{2}(x, t)=-S^{-1}\left(u^{\alpha} S\left[L[x] u_{1}(x, t)+H_{1}(u)\right]\right), \\
& p^{3}: u_{3}(x, t)=-S^{-1}\left(u^{\alpha} S\left[L[x] u_{2}(x, t)+H_{2}(u)\right]\right),
\end{aligned}
$$


Proceeding in the same manner, the rest of the components $u_{n}(x, t)$ can be completely obtained, and the series solution is thus entirely determined. Finlay we approximate the solution $u(x, t)$ by truncated series

$$
u(x, t)=\lim _{N \rightarrow \infty} \sum_{n=0}^{N} u_{n}(x, t)
$$

This series solutions generally converge very rapidly.

\section{Examples}

In this section, we discuss the implementation of the proposed method.

Example 6. We consider the following fractional BlackScholes option pricing equation as follows:

$$
\frac{\partial^{\alpha} v}{\partial t^{\alpha}}=\frac{\partial^{2} v}{\partial x^{2}}+(k-1) \frac{\partial v}{\partial x}-k v, \quad 0<\alpha \leq 1
$$

subject to initial condition

$$
v(x, 0)=\max \left(e^{x}-1,0\right) .
$$

Applying Sumudu transform on both sides of (29) subject to initial condition (30), we get

$$
\begin{aligned}
S[ & {[v(x, t)] } \\
& =\max \left(e^{x}-1,0\right)+u^{\alpha} S\left[v_{x x}+(k-1) v_{x}-k v\right] .
\end{aligned}
$$

Operating the inverse Sumudu transform on both sides in (31), we have

$v(x, t)=\max \left(e^{x}-1,0\right)-S^{-1}\left[u^{\alpha} S\left(v_{x x}+(k-1) v_{x}-k v\right)\right]$.

Now, applying homotopy perturbation method

$$
\begin{aligned}
& \sum_{n=0}^{\infty} p^{n} v_{n}(x, t) \\
& \quad=\max \left(e^{x}-1,0\right)-p\left(S^{-1}\left[u^{\alpha} S\left[\sum_{n=0}^{\infty} p^{n} H_{n}(v)\right]\right]\right)
\end{aligned}
$$

where

$$
H_{n}=v_{n x x}+(k-1) v_{n x}+k v_{n}, \quad n \in N \text {. }
$$

Equating the corresponding power of $p$ on both sides in (38), we have

$$
\begin{aligned}
& p^{0}: v_{0}(x, t)=\max \left(e^{x}-1,0\right), \\
& p^{1}: v_{1}(x, t)=S^{-1}\left(u^{\alpha} S\left[H_{0}(v)\right]\right) \\
& =-\max \left(e^{x}, 0\right) \frac{\left(-k t^{\alpha}\right)}{\Gamma(\alpha+1)} \\
& +\max \left(e^{x}-1,0\right) \frac{\left(-k t^{\alpha}\right)}{\Gamma(\alpha+1)}, \\
& p^{2}: v_{2}(x, t)=S^{-1}\left(u^{\alpha} S\left[H_{1}(v)\right]\right) \\
& =\max \left(e^{x}, 0\right) \frac{\left(-k t^{\alpha}\right)^{2}}{\Gamma(2 \alpha+1)} \\
& +\max \left(e^{x}-1,0\right) \frac{\left(-k t^{\alpha}\right)^{2}}{\Gamma(2 \alpha+1)}, \\
& p^{n}: v_{n}(x, t)=S^{-1}\left(u^{\alpha} S\left[H_{n}(v)\right]\right) \\
& =\max \left(e^{x}, 0\right) \frac{\left(-k t^{\alpha}\right)^{n}}{\Gamma(n \alpha+1)} \\
& +\max \left(e^{x}-1,0\right) \frac{\left(-k t^{\alpha}\right)^{n}}{\Gamma(n \alpha+1)} .
\end{aligned}
$$

So that the solution $v(x, t)$ of the problem is given by

$$
\begin{aligned}
v(x, t)= & \lim _{p \rightarrow 1} \sum_{i=0}^{\infty} p^{i} u_{i}(x, t) \\
= & \max \left(e^{x}-1,0\right) E_{\alpha}\left(-k t^{\alpha}\right) \\
& +\max \left(e^{x}, 0\right)\left(1-E_{\alpha}\left(-k t^{\alpha}\right)\right),
\end{aligned}
$$

where $E_{\alpha}(z)$ is Mittag-Leffler function in one parameter. For special case $\alpha=1$, we get

$$
\begin{aligned}
v(x, t)= & \max \left(e^{x}-1,0\right) e^{-k t} \\
& +\max \left(e^{x}, 0\right)\left(1-e^{-k t}\right),
\end{aligned}
$$

which is an exact solution of the given Black-Scholes equation (29) for $\alpha=1$.

The behaviour of $v(x, t)$ with respect to $x$ and $t$ when $\alpha=$ 1 is given in Figure 1.

Example 7. We consider the following fractional BlackScholes option pricing equation as follows:

$$
\frac{\partial^{\alpha} v}{\partial t^{\alpha}}+0.08(2+\sin x)^{2} x^{2} \frac{\partial^{2} v}{\partial x^{2}}+0.06 \frac{\partial v}{\partial x}-0.06 v=0
$$




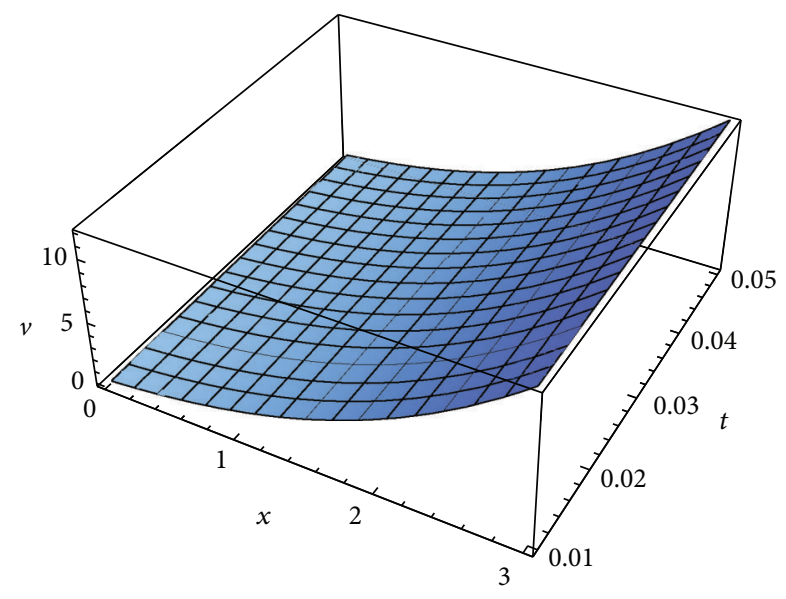

FIGURE 1: The surface shows the $v(x, t)$ for (29) with respect to $x$ and $t$ for $\alpha=1$.

subject to initial condition

$$
v(x, 0)=\max \left(x-25 e^{-0.06}, 0\right)
$$

Firstly, applying Sumudu transform on both sides of (38) subject to initial condition (39), we get

$$
\begin{aligned}
S[v(x, t)]= & \max \left(x-25 e^{-0.06}, 0\right)-u^{\alpha} S \\
& \times\left[0.08(2+\sin x)^{2} x^{2} v_{x x}+0.06 v_{x}-0.06 v\right] .
\end{aligned}
$$

Operating the inverse Sumudu transform on both sides in (40), we have

$$
\begin{aligned}
v(x, t)= & \max \left(x-25 e^{-0.06}, 0\right)-S^{-1} \\
& \times\left[u^{\alpha} S\left(0.08(2+\sin x)^{2} x^{2} v_{x x}+0.06 v_{x}-0.06 v\right)\right] .
\end{aligned}
$$

Now, applying the homotopy perturbation method we have

$$
\begin{aligned}
\sum_{n=0}^{\infty} p^{n} v_{n}(x, t)= & \max \left(x-25 e^{-0.06}-1,0\right) \\
& -p\left(S^{-1}\left[u^{\alpha} S\left[\sum_{n=0}^{\infty} p^{n} H_{n}(v)\right]\right]\right),
\end{aligned}
$$

where

$$
H_{n}=0.08(2+\sin x)^{2} x^{2} v_{n x x}+0.06 v_{n x}-0.06 v_{n}, \quad n \in N
$$

Equating the corresponding power of $p$ on both sides in (42), we have

$$
\begin{aligned}
p^{0} & : v_{0}(x, t)=\max \left(x-25 e^{-0.06}, 0\right) \\
p^{1}: & v_{1}(x, t) \\
& =S^{-1}\left(u^{\alpha} S\left[H_{0}(v)\right]\right) \\
& =-x \frac{\left(-0.06 t^{\alpha}\right)}{\Gamma(\alpha+1)}+\max \left(x-25 e^{-0.06}, 0\right) \frac{\left(-0.06 t^{\alpha}\right)}{\Gamma(\alpha+1)} \\
p^{2}: & v_{2}(x, t) \\
= & S^{-1}\left(u^{\alpha} S\left[H_{1}(v)\right]\right) \\
= & -x \frac{\left(-0.06 t^{\alpha}\right)^{2}}{\Gamma(2 \alpha+1)}+\max \left(x-25 e^{0.06}, 0\right) \frac{\left(-0.06 t^{\alpha}\right)^{2}}{\Gamma(2 \alpha+1)} \\
& \vdots \\
p^{n}: & v_{n}(x, t)=S^{-1}\left(u^{\alpha} S\left[H_{n}(v)\right]\right) \\
& +\max \left(x-25 e^{x}, 0\right) \frac{\left(-0.06-t^{\alpha}\right)^{n}}{\Gamma(n \alpha+1)} . \\
= & -x \frac{\left(-0.06 t^{\alpha}\right)^{n}}{\Gamma(n \alpha+1)}
\end{aligned}
$$

So that the solution $v(x, t)$ of the problem is given by

$$
\begin{aligned}
v(x, t)= & \lim _{p \rightarrow 1} \sum_{i=0}^{\infty} p^{i} u_{i}(x, t) \\
= & x\left(1-E_{\alpha}\left(-0.06 t^{\alpha}\right)\right) \\
& +\max \left(x-25 e^{-0.06}, 0\right) E_{\alpha}\left(-0.06 t^{\alpha}\right) .
\end{aligned}
$$

This is the exact solution of the given option pricing equation (38). The solution of (38) at the special case $\alpha=1$ is

$$
\begin{aligned}
v(x, t)=x & \left(1-e^{0.06 t}-1,0\right) \\
& +\max \left(x-25 e^{-0.06}, 0\right) e^{-0.06 t} .
\end{aligned}
$$

The behaviour of $v(x, t)$ with respect to $x$ and $t$ when $\alpha=1$ is given in Figure 2.

\section{Conclusion}

In this paper, the homotopy perturbation Sumudu transform method (HPSTM) is successfully applied for getting the analytical solution of the fractional Black-Scholes option pricing equation. Two examples from the literature [26] are presented. The results of the illustrated examples are in agreement with the results of the method presented in [26]. In conclusion, HPSTM is a very powerful and efficient method to find approximate solutions as well as numerical solutions. 


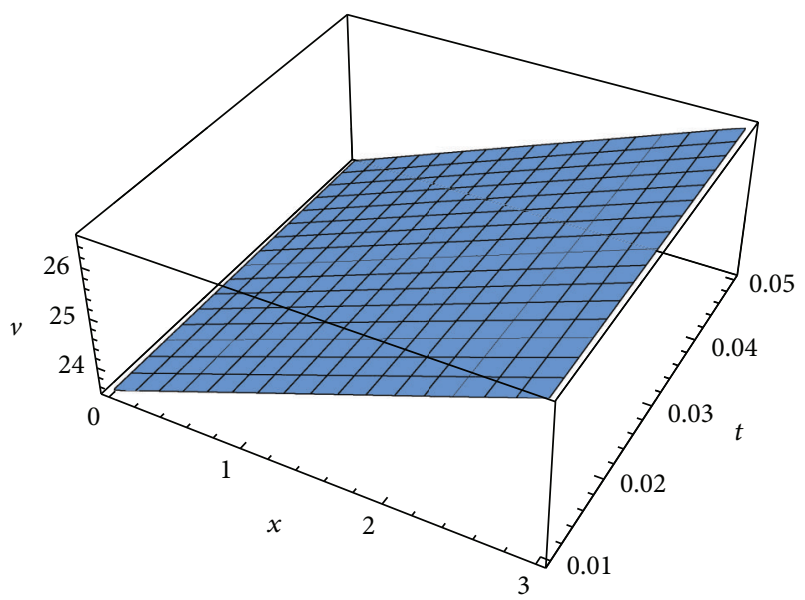

Figure 2: The surface shows the $v(x, t)$ for (38) with respect to $x$ and $t$ for $\alpha=1$.

\section{Acknowledgment}

The authors express their sincere thanks to the referees for the careful and noteworthy reading of the paper, and the very helpful suggestions that improved the paper substantially.

\section{References}

[1] I. Podlubny, Fractional Differential Equations, vol. 198 of Mathematics in Science and Engineering, Academic Press, San Diego, Calif, USA, 1999.

[2] A. A. Kilbas, H. M. Srivastava, and J. J. Trujillo, Theory and Applications of Fractional Differential Equations, vol. 204 of North-Holland Mathematics Studies, Elsevier, Amsterdam, The Netherlands, 2006.

[3] V. Lakshmikantham, S. Leela, and J. V. Devi, Theory of Fractional Dynamic Systems, Cambridge Scientific, Cambridge, UK, 2009.

[4] D. Baleanu, K. Diethelm, E. Scalas, and J. J. Trujillo, Fractional Calculus Models and Numerical Methods, Series on Complexity, Nonlinearity and Chaos, World Scientific, Singapore, 2012.

[5] K. S. Miller and B. Ross, An Introduction to the Fractional Calculus and Fractional Differential Equations, Wiley-Interscience; John Wiley \& Sons, New York, NY, USA, 1993.

[6] R. Metzler, W. Schick, H. G. Kilian, and T. F. Nonnenmacher, "Relaxation in filled polymers: a fractional calculus approach," The Journal of Chemical Physics, vol. 103, no. 16, pp. 7180-7186, 1995.

[7] H. Beyer and S. Kempfle, "Definition of physically consistent damping laws with fractional derivatives," Zeitschrift für Angewandte Mathematik und Mechanik, vol. 75, no. 8, pp. 623-635, 1995.

[8] L. Debnath, "Fractional integral and fractional differential equations in fluid mechanics," Fractional Calculus \& Applied Analysis, vol. 6, no. 2, pp. 119-155, 2003.

[9] K. B. Oldham and J. Spanier, The Fractional Calculus: Theory and Applications of Differentiation and Integration to Arbitrary Order, vol. 111 of Mathematics in Science and Engineering, Academic Press, New York, NY, USA, 1974, with an annotated chronological bibliography by Bertram Ross.
[10] M. Bohner and Y. Zheng, "On analytical solutions of the BlackScholes equation," Applied Mathematics Letters, vol. 22, no. 3, pp. 309-313, 2009.

[11] R. Company, E. Navarro, J. R. Pintos, and E. Ponsoda, "Numerical solution of linear and nonlinear Black-Scholes option pricing equations," Computers \& Mathematics with Applications, vol. 56, no. 3, pp. 813-821, 2008.

[12] Z. Cen and A. Le, "A robust and accurate finite difference method for a generalized Black-Scholes equation," Journal of Computational and Applied Mathematics, vol. 235, no. 13, pp. 3728-2733, 2011.

[13] J. Ankudinova and M. Ehrhardt, "On the numerical solution of nonlinear Black-Scholes equations," Computers \& Mathematics with Applications, vol. 56, no. 3, pp. 799-812, 2008.

[14] V. Gülkaç, "The homotopy perturbation method for the BlackScholes equation," Journal of Statistical Computation and Simulation, vol. 80, no. 12, pp. 1349-1354, 2010.

[15] J.-H. He, "Homotopy perturbation technique," Computer Methods in Applied Mechanics and Engineering, vol. 178, no. 3-4, pp. 257-262, 1999.

[16] J.-H. He, "A coupling method of a homotopy technique and a perturbation technique for non-linear problems," International Journal of Non-Linear Mechanics, vol. 35, no. 1, pp. 37-43, 2000.

[17] J.-H. He, "Some asymptotic methods for strongly nonlinear equations," International Journal of Modern Physics B, vol. 20, no. 10, pp. 1141-1199, 2006.

[18] J.-H. He, "The homotopy perturbation method nonlinear oscillators with discontinuities," Applied Mathematics and Computation, vol. 151, no. 1, pp. 287-292, 2004.

[19] J. H. He, "Application of homotopy perturbation method to nonlinear wave equations," Chaos, Solitons and Fractals, vol. 26, no. 3, pp. 695-700, 2005.

[20] S. Momani and Z. Odibat, "Homotopy perturbation method for nonlinear partial differential equations of fractional order," Physics Letters A, vol. 365, no. 5-6, pp. 345-350, 2007.

[21] A. A. Elbeleze, A. Kılıçman, and B. M. Taib, "Application of homotopy perturbuation and variational iteration method for Fredholm integro-differential equation of fractional ordef," Abstract \& Applied Analysis, vol. 2012, Article ID 763139, 14 pages, 2012.

[22] H. Jafari and C. M. Khalique, "Homotopy perturbation and variational iteration methods for solving fuzzy differential equations," Communications in Fractional Calculus, vol. 3, pp. 38-48, 2012.

[23] Y. M. Qin and D. Q. Zeng, "Homotopy perturbation method for the q-diffusion equation with a source term," Communications in Fractional Calculus, vol. 3, no. 1, pp. 34-37, 2012.

[24] M. Gorji, D. D. Ganji, and S. Soleimani, "New application of He's homotopy perturbation method," International Journal of Nonlinear Sciences and Numerical Simulation, vol. 8, no. 3, pp. 319-328, 2007.

[25] M. Madani, M. Fathizadeh, Y. Khan, and A. Yildirim, "On the coupling of the homotopy perturbation method and Laplace transformation," Mathematical and Computer Modelling, vol. 53, no. 9-10, pp. 1937-1945, 2011.

[26] S. Kumar, A. Yildirim, Y. Khan, H. Jafari, K. Sayevand, and L. Wei, "Analytical solution of fractional Black-Scholes European option pricing equation by using Laplace transform," Journal of Fractional Calculus and Applications, vol. 2, no. 8, pp. 1-9, 2012.

[27] M. Javidi and M. A. Raji, "Combination of Laplace transform and homotopy perturbation method to solve the parabolic 
partial differential equations," Communications in Fractional Calculus, vol. 3, pp. 10-19, 2012.

[28] J. Singh, D. Kumar, and Sushila, "Homotopy perturbation Sumudu transform method for nonlinear equations," Advances in Applied Mathematics and Mechanics, vol. 4, pp. 165-175, 2011.

[29] J. Singh, D. Kumar, and A. Kiliçman, "Homotopy perturbation method for fractional gas dynamics equation using Sumudu transform," Abstract and Applied Analysis, vol. 2013, Article ID 934060, 8 pages, 2013.

[30] G. K. Watugala, "Sumudu transform-a new integral transform to solve differential equations and control engineering problems," Mathematical Engineering in Industry, vol. 6, no. 4, pp. 319-329, 1998.

[31] M. A. Așiru, "Further properties of the Sumudu transform and its applications," International Journal of Mathematical Education in Science and Technology, vol. 33, no. 3, pp. 441-449, 2002.

[32] F. B. M. Belgacem, A. A. Karaballi, and S. L. Kalla, "Analytical investigations of the Sumudu transform and applications to integral production equations," Mathematical Problems in Engineering, no. 3-4, pp. 103-118, 2003.

[33] H. Eltayeb, A. Kılıçman, and B. Fisher, "A new integral transform and associated distributions," Integral Transforms and Special Functions, vol. 21, no. 5-6, pp. 367-379, 2010.

[34] A. Kılıçman, V. G. Gupta, and B. Sharma, "On the solution of fractional Maxwell equations by Sumudu transform," Journal of Mathematics Research, vol. 2, no. 4, pp. 147-151, 2010.

[35] A. Kılıçman and H. Eltayeb, "A note on integral transforms and partial differential equations," Applied Mathematical Sciences, vol. 4, no. 6, pp. 109-118, 2010.

[36] M. A. Asiru, "Sumudu transform and the solution of integral equations of convolution type," International Journal of Mathematical Education in Science and Technology, vol. 32, no. 6, pp. 906-910, 2001.

[37] A. Kadem, "Solving the one-dimensional neutron transport equation using Chebyshev polynomials and the Sumudu transform," Analele Universitatiidin Oradea. Fascicola Matematica, vol. 12, pp. 153-171, 2005.

[38] A. Kılıçman and H. E. Gadain, "On the applications of Laplace and Sumudu transforms," Journal of the Franklin Institute, vol. 347 , no. 5, pp. 848-862, 2010.

[39] A. Kiliçman, H. Eltayeb, and R. P. Agarwal, "On Sumudu transform and system of differential equations," Abstract and Applied Analysis, vol. 2010, Article ID 598702, 11 pages, 2010.

[40] V. B. L. Chaurasia and J. Singh, "Application of Sumudu transform in Schödinger equation occurring in quantum mechanics," Applied Mathematical Sciences, vol. 4, no. 57-60, pp. 28432850, 2010.

[41] S. J. Liao, "An approximate solution technique not depending on small parameters: a special example," International Journal of Non-Linear Mechanics, vol. 30, no. 3, pp. 371-380, 1995.

[42] S. J. Liao, "Boundary element method for general nonlinear differential operator," Engineering Analysis with Boundary Elements, vol. 20, no. 2, pp. 91-99, 1997.

[43] J.-H. He, "Asymptotic methods for solitary solutions and compactons," Abstract and Applied Analysis, vol. 2012, Article ID 916793, 130 pages, 2012.

[44] A. Ghorbani and J. S. Nadjfi, "He's homotopy perturbation method for calculating Adomian's polynomials," The International Journal of Nonlinear Sciences and Numerical Simulation, vol. 8, no. 2, pp. 229-332, 2007.
[45] A. Ghorbani, "Beyond Adomian polynomials: he polynomials," Chaos, Solitons and Fractals, vol. 39, no. 3, pp. 1486-1492, 2009. 


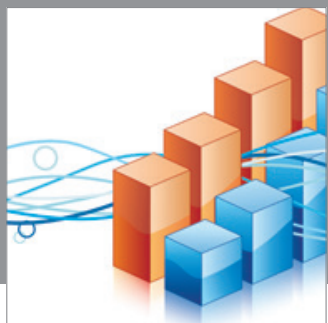

Advances in

Operations Research

mansans

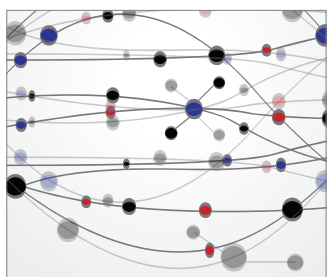

The Scientific World Journal
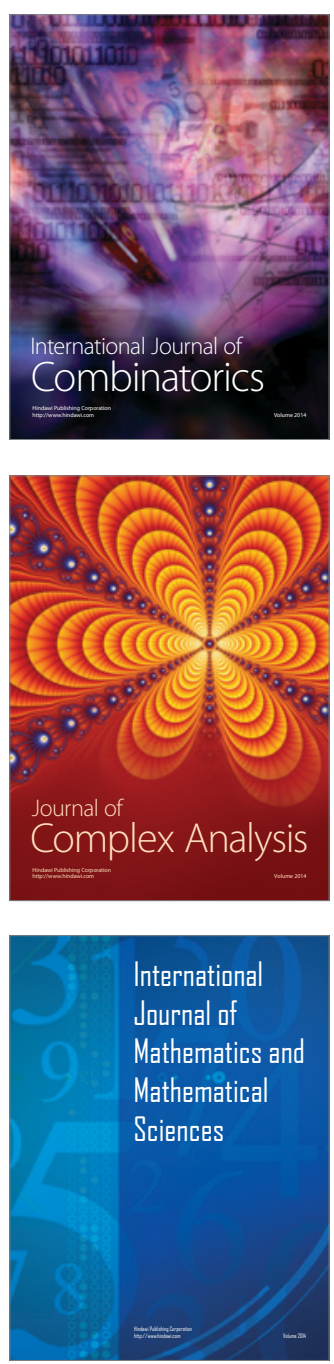
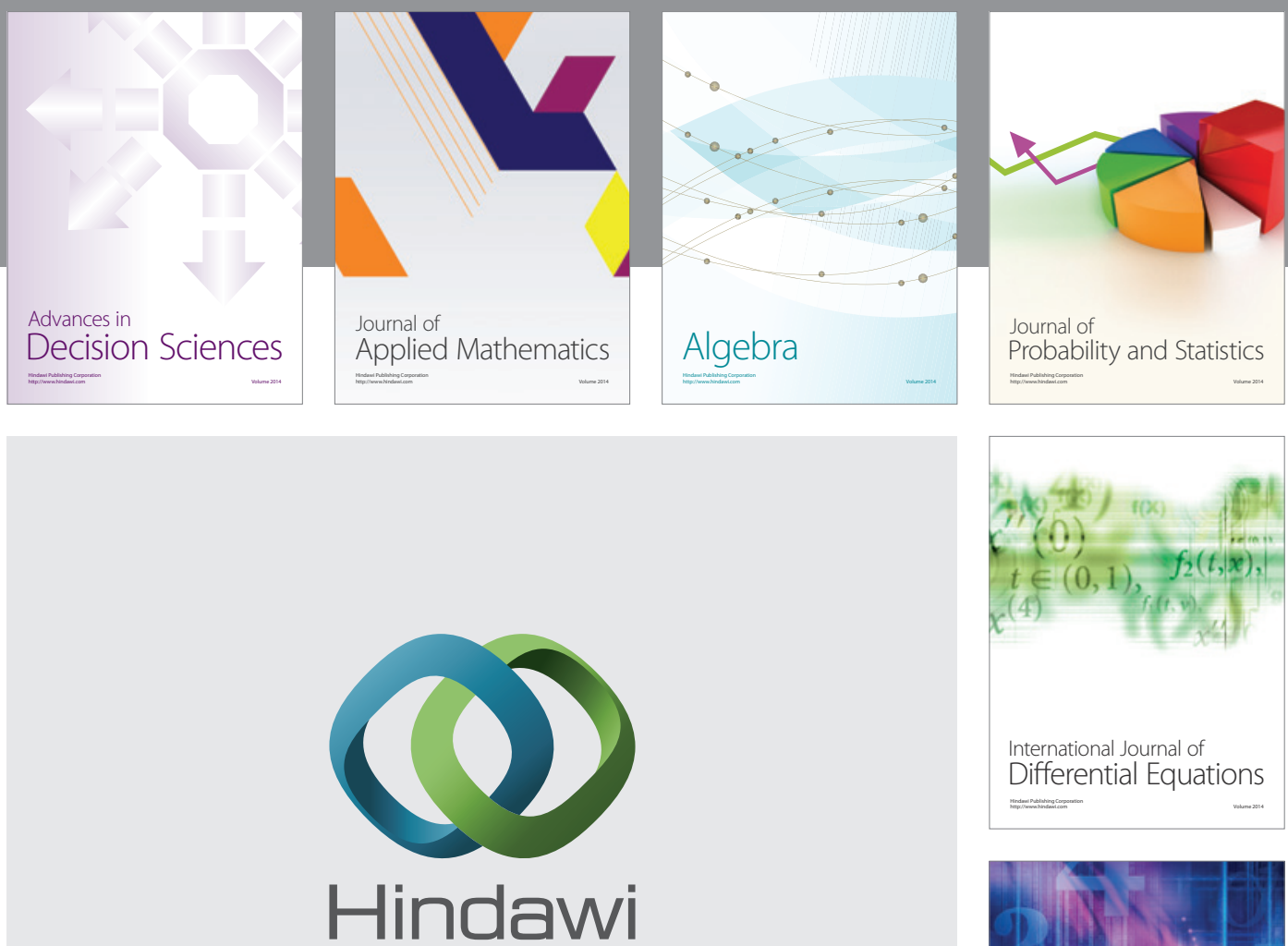

Submit your manuscripts at http://www.hindawi.com
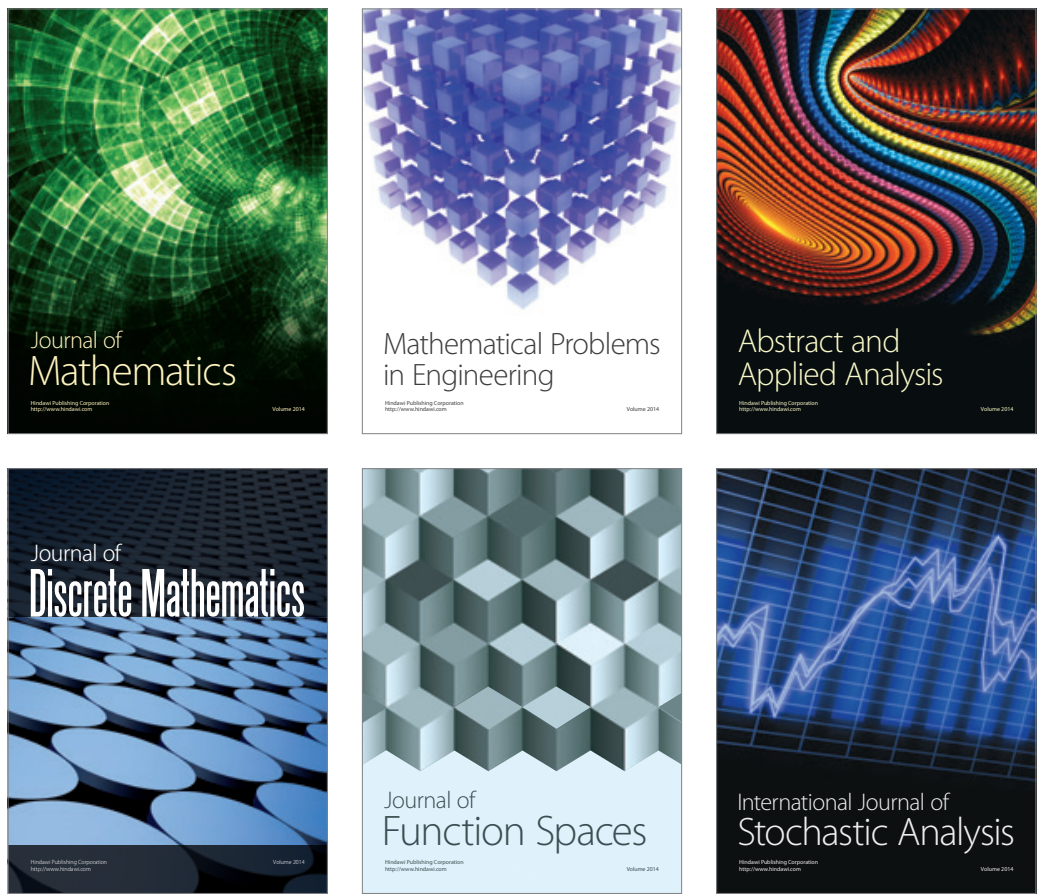

Journal of

Function Spaces

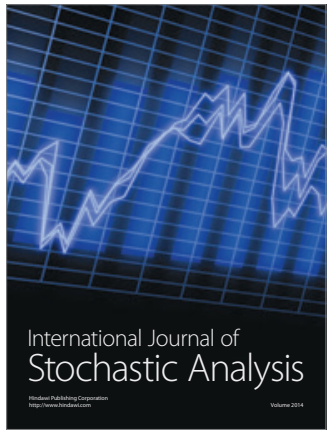

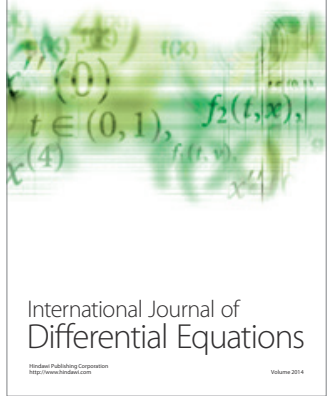
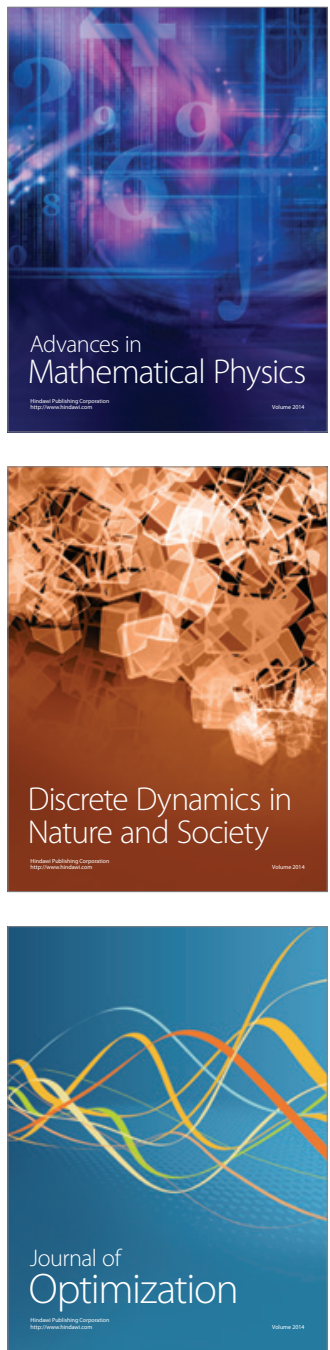